\title{
COMBATING HYDROGEN EMBRITTLEMENT WITH GRAPHENE BASED COATINGS
}

\author{
Amit Khare*, Dr. Manish Vishwakarma, Dr. Siraj Ahmed \\ Mechanical Engineering Department, \\ Maulana Azad National Institute of Technology, Bhopal, India \\ *Corresponding Author Email: amitkhare.bhel@gmail.com
}

\begin{abstract}
Hydrogen embrittlement (HE) is an epidemic problem for high strength medium carbon low alloy steel causing reduction in mechanical strength and useful service lifetime. Hydrogen embrittlement of high strength steel is concern for various industrial components used in critical applications. Unpredictable \& sudden failure of mechanical equipment/components made of high strength steel (HSS) below designed allowable stress and without appreciable deformation resulted in many catastrophic accidents. HSS being used in various engineering applications such as Aerospace, Nuclear, Marine and Transportation etc. Components typically affected by hydrogen embrittlement are pressure vessels, boilers, automobile frame, fasteners \& hardware, shafts, axles, rotors, pipelines etc. Extensive research has been done by scientists \& engineers to explore various ways to prevent hydrogen embrittlement. Some of them are i) addition of alloying elements ii) selection of material with less susceptibility to hydrogen iii) use of barrier layers to prevent hydrogen diffusion iv) change in manufacturing process and application environment v) use of advance Nano coatings to minimize hydrogen penetration etc. Out of all these methods of controlling hydrogen embrittlement, use of advance coatings appears to be more practical, less intricate and economical. In current decade Graphene has achieved a great attention from engineering world because of its excellent chemical, physical, mechanical \& thermal properties. Graphene can act as a protective barrier against many environmental induced degradation of alloy steels because of its extraordinary impermeability. This review article summaries the current state of research \& available commercial solutions for mitigations of hydrogen embrittlement using graphene based Nanocoatings. Authors have conducted experiments on several available coatings including graphene to investigate the behavior in an environment promoting hydrogen embrittlement and compared the effect on mechanical properties and ductility of high strength steel (EN24/AISI4340/34CrNiMo6)
\end{abstract}

Keywords: Hydrogen Embrittlement, High strength steel, Nano coatings, Graphene.

Cite this Article: Amit Khare, Dr. Manish Vishwakarma, Dr. Siraj Ahmed, Combating Hydrogen Embrittlement with Graphene Based Coatings, International Journal of Advanced Research in Engineering and Technology, 10(6), 2019, pp. 234-251.

http://iaeme.com/Home/issue/IJARET?Volume $=10 \&$ Issue $=6$ 


\section{INTRODUCTION TO HYDROGEN EMBRITTLEMENT}

As Introduced by Johnson [1] in year 1875, the presence of atomic hydrogen leads to the reduction in ductility of a material is known as hydrogen embrittlement. The hydrogen embrittlement phenomenon as per ASTM F2078[2-3] is defined as "An irreversible loss of ductility in a metallic alloys caused due to infusion of hydrogen with combining stresses, whether its internally or externally applied residual stresses". Hydrogen embrittlement may result to transform high strength steel from ductile to brittle by absorbtion and subsequent distribution of hydrogen in microstructure making them susceptible to fracture. Hydrogen can enter into high strength (HS) steel during galvanizing, pickling, cleaning, electroplating, phosphating and in the service environment [4].

The fracture phenomena use the term hydrogen embrittlement caused due to the infusion of hydrogen atoms \& also acknowledged as hydrogen accelerated failure or hydrogen induced degradation. Those material which are most sensitive include HS steels \& alloys, Ti \& Al alloys and $\mathrm{Cu}$ alloys [5]. Embrittlement due to hydrogen might deteriorate mechanical properties and leads to delayed breakdown which can take place due to externally applied stresses or internal residual stresses and at times ductile material becomes brittle [6,7]. Additionally, the mechanical properties may further deteriorate due to slow straining which indicates strain dependent transmission of diffused hydrogen as a contributing parameter. HE is usually predominant at ambient temperature, however while heating is done hydrogen stored at grain boundaries may get depleted.

Two possible mechanisms of hydrogen embrittlement in metals are explained by Troiano [8]. One is deposition of atomic hydrogen at crack roots which diminishes the energy for crack propagation resulting in cleavage-like fracture [8,9]. The other mechanism resulting in failure on account of increase in local plasticity due to high movement of dislocations through an elastic shielding effect [10]. However, the process by which hydrogen reacting with material is entirely different. As the HE is result of collaboration between induced hydrogen and externally applied loads, therefore mitigation theories are primarily focusing on two aspects first is removal of induced hydrogen and second is to provide barriers to hydrogen entry that includes heat treatment [11], neon/helium glow discharge [12], inhibitors of hydrogen permeation [13], and protective barriers [14]. We shall discuss and elaborate on how the recent advances in the area of Nano coatings technology can be harvested to help engineers and scientists while dealing with hydrogen embrittlement.

\subsection{Introduction to Nano Materials \& Nano Coatings}

Coatings are being widely used in preventing, minimizing and controlling the effect of external environment on the metallic and non-metallic substrate. [15]. Coatings creates a barrier film between parent metal and external environment and applying a coating protect components from direct exposure however this might have an additional cost but proven to be economical over a longer duration when applied on the large volume, resulting in improvement in reliability $\&$ reduction in maintenance cycle with lesser chances of failure and enhanced service life [16]. Degradation of base material can be prevented by providing passive [17] or active protection [18]. Passive prevention is done by providing a physical barrier of oxides between object and the surrounding atmosphere [19] hence damage is prevented by mechanically isolating the base material from the aggressive surrounding agents. Active protection is achieved by adding chemicals (inhibitors) to aggressive environments to prevent or minimize damage. The aim of active corrosion protection is to influence the reactions which take place in the process of material degradation. 
ISO/TS 80004 describes nanomaterial as the "material with any external dimension in the nanoscale or having internal structure or surface structure in the nanoscale", \& nanoscale explained as the "length range approximately from $1 \mathrm{~nm}$ to $100 \mathrm{~nm}$ ". Further On 18 October 2011, the European Commission defined nanomaterial as: "A natural, incidental or manufactured material containing particles, in an unbound state or as an aggregate or as an agglomerate and for $50 \%$ or more of the particles in the number size distribution, one or more external dimensions is in the size range $1 \mathrm{~nm}-100 \mathrm{~nm} .[14]$

Nanomaterials are ultrathin materials having any one morphological dimension as such as grain/ particle/ structure size in the nanoscale (less than $100 \mathrm{~nm}$ ) [18]. These could exist in the form of nanoparticles / nanotubes / nanowires / nanorods / nanoplatelet / nanosheets / nanofilms. Nanomaterials displays enhanced physical, magnetic, optical, thermal, mechanical, chemical, electronic properties [21] mainly due to Nano sizes, which manifests in higher surface area to volume ratios and thereby large interaction areas [20]. Nano materials are considered to have promising future while dealing with aggressive environmental condition e.g. corrosion, exposure to acidic medium, marine and cryogenic application \& embrittlement problem on account of hydrogen diffusion. Nano coatings contains very thin layers that are in the range of $100 \mathrm{~nm}[23,24]$. Nanostructured coatings possess properties that are altogether different from the conventional coatings making them most appropriate to be used for formation of protective layers.

Coatings are differentiated on the basis of constituent materials which could be metallic, ceramic or polymer based coatings. As a basic science in providing protection the coatings block the environmental elements from entering into the surface of the parent metal by offering high density at grain boundaries attributed for better adhesion properties resulting in increased life of industrial components. [6]. Coatings have superior mechanical and electronic properties making them tougher, harder [25] resulting in better resistance to environments responsible for damage e.g. corrosion, wear and hydrogen embrittlement [26]. Behavior of Nano additive coatings is completely different than the conventional coatings of microsized particles for example, corrosion resistance of traditional zinc coatings could greatly enchanced by adding CNT [32].

Various deposition methods to obtain Nanocoatings are listed below in Table-1 [37].

Table 1 Methods for Thin Film Deposition

\begin{tabular}{|l|c|c|c|c|}
\hline \multicolumn{5}{c}{ Thin Film Deposition } \\
\hline \multicolumn{1}{|c|}{ Physical } & Chemical & Mechanical \\
\hline Bonding & Condensation & Sputter & Plating & bonding \\
\hline Diffusion & PVD & Magnetron & VLS & Brush painting \\
\hline Brazing & LPE & MBE & PECVD & Spray painting \\
\hline SAB & & Laser PLD & MOCVD & Dip Coat \\
\hline SLS & & & ALD & \\
\hline 3D Printing & & & Sol-Gel & \\
\hline
\end{tabular}

\section{GRAPHENE: AN EXCELLENT NANO MATERIAL}

Graphene is a flat monolayer of carbon atoms tightly packed into a two-dimensional (2D) honeycomb lattice, and is a basic building block for graphitic materials (Figure 1). It can be wrapped up into 0D, rolled into 1D nanotubes or stacked into 3D graphite.[39]

After synthesis and characterization of graphene in 2004 by British scientist Andre Geim and Russian scientist Konstantis Novoselov [38], this two-dimensional (2D) material has attracted continued interest due to its remarkable structural and electronic properties [39]. Graphene first produced by simple mechanical exfoliation known as the thinnest two- 
dimensional carbon material. The initial graphene with a single layer of carbon atoms was stripped off from of highly ordered pyrolytic graphite (HOPG) [1] graphite by micromechanical cleavage (scotch tape method) on a sticky tape. The discovery of graphene opened up new areas for research of carbon materials. Geim and Novoselov won the Nobel Prize in Physics in 2010 for their great discovery



Figure 1 Graphene is a 2D building material for carbon materials [39]

Graphene has one atom thick planer sheet like structure with hexagonally arranged sp2 bonded carbon atom network making it different from other materials and responsible for its highest strength among the materials currently found. Its tensile strength is $130 \mathrm{GPa}$ and Young's modulus is as high as $1 \mathrm{TPa}$. In terms of other physical characteristics, graphene has a high conductivity of $6 \times 10^{5} \mathrm{~S} / \mathrm{m}$, thermal conductivity of $3000 \mathrm{Wm}^{-1} \mathrm{~K}^{-1}$ and specific surface area of $2600 \mathrm{~m}^{2} / \mathrm{g}$.

Few important properties of graphene are described below -

\subsection{Electronic Properties}

Graphene is a very high electrical conductivity material. In its atomic structure Carbon atoms contain a total of 6 electrons; 2 in the inner orbit and 4 in the outer orbit. The 4 outer orbit electrons in an individual carbon atom are available for chemical bonding, but in graphene, each atom is linked to 3 other carbon atoms in a two dimensional plane, resulting in 1 electron freely available in the third dimension for electronic conduction. These highly-mobile electrons are called pi $(\pi)$ electrons and are located above and below the graphene layer. These pi orbitals overlap and help to enhance the carbon to carbon bonds in graphene. Fundamentally, the electronic properties of graphene are dictated by the bonding and anti-bonding (the valance and conduction bands) of these pi orbitals.

Graphene possess extremely high electrical current density (a million times that of copper) and intrinsic mobility (100 times that of silicon). Its resistivity is lower than any other known material at room temperature, including silver. There are also some methods to turn it into a superconductor (it can carry electricity with $100 \%$ efficiency). 


\subsection{Thermal Properties}

Graphene is an excellent thermal conductor. The thermal conductivity of graphene is derived by phonons and found approximately $5000 \mathrm{Wm}^{-1} \mathrm{~K}^{-1}$. Which is 10 times better than copper. This is the highest among any known material. [42] Graphene's extraordinary conductivity makes it an ideal material for heat management systems.

The thermal conductivity of graphene increases logarithmically due to the stable bonding pattern as well as being a 2D material. Graphene's enormous strength to tear and shear along with its lightweight and flexible structure and excellent conductive properties place it as a magic material with numerous remarkable real-world applications. Graphene has very high in-plane thermal conductivity and relatively low out-of-plane thermal conductance. The specific heat of graphene is little higher than that of graphite and diamond below room temperature [41].

\subsection{Mechanical Properties}

Graphene having a carbon-carbon bond length of about 0.142 nanometers and inter planar spacing in graphene sheets stack to form graphite lies in a range of of $0.335 \mathrm{~nm}$. Graphene is the strongest material ever tested with an intrinsic tensile strength of $130 \mathrm{GPa}$ and a Young's modulus of $1 \mathrm{TPa}$. Thus, graphene is more than 100 times stronger than the strongest steel. This very famous Nobel announcement illustrate the fact by saying that a 1 square meter graphene hammock would support a $4 \mathrm{~kg}$ cat but would weigh only as much as one of the cat's whiskers, at $0.77 \mathrm{mg}$ (about $0.001 \%$ of the weight of $1 \mathrm{~m}^{2}$ of paper) [42].

Furthermore, the excellent mechanical properties of graphene can be exploited to reinforce polymer matrix. If graphene Nano platelets are loaded with a fraction of $0.1 \%$ in a polymer matrix, the overall mechanical properties of the composite structure, in terms of Young's modulus and tensile strength are enormously scaled up [43].

\subsection{Impermeability}

Graphene displays extremely high impermeability to all gases including Hydrogen \& Helium [101-102]. A high quality single layer graphene is impermeable even to hydrogen atoms at ambient conditions eventually on account of dense electronic structure of graphene. This characteristic shall be further discussed in detail in other sections.

Due to its exceptional electronic, thermal, mechanical, and optical properties in addition to its large surface area and single-atom thickness as explained above, GRAPHENE is attributed as miracle material and leading to the discovery of several new techniques to obtain graphene other than conventional such as chemical exfoliation, chemical vapor deposition (CVD), chemical synthesis etc. However, the mammoth challenge is to produce graphene in large quantities \& high quality with fewer defects. Several experiments have been carried out to explore new methods to producing high-quality graphene for use by industries in large scale.

\section{SYNTHESIS OF GRAPHENE: FABRICATION METHOD}

Extraction or fabrication of desired size and quality of graphene is termed as synthesis of graphene. In $20^{\text {th }}$ century research was primarily focused on producing thin graphite film in form of graphite layers on metal surfaces. B.Lang demonstrated the first successful deposition of carbon on platinum crystal surfaces in 1975 [44]. Many other miraculous thermal, electronic, mechanical and optical properties of graphene could not be discovered and investigated during that period owing to the limitation of characterization techniques and its application. In 1999 Xuekun Lu, S. Ruoff et. Demonstrated \#"Patterning of highly oriented pyrolytic graphite (HOPG) by oxygen plasma etching [45] to obtained single sheet graphite. Highly oriented pyrolytic graphite [HOPG] is a manmade material which is polycrystalline with highly oriented graphene sheets; the typical domain size in HOPG is $1-10 \mu \mathrm{m}$ in the basal plane and $.0 .1 \mu \mathrm{m}$ 
perpendicular to the basal plane. These are found useful in further studies of mechanical, chemical and biological properties of very thin graphite platelets.

A breakthrough occurred in 2004 when Geim and Novoselov published their study for isolating graphe on $\mathrm{SiO} 2$ substrate and demonstrated electric field effect in atomically thin carbon films. [39, 40]. This discovery opened an entirely new arena of possibilities for physicist, biologist \& material scientist resulted in development of various new techniques to produce thin graphene films.

In last 10 years, a number of methods are developed for graphene synthesis by researchers. Most common techniques are Mechanical exfoliation [38], chemical synthesis [46], chemical exfoliation [47] [48], epitaxial growth [49], and thermal chemical vapor deposition (CVD) [50]. In 2009, Kosynkin et. Developed a unique method of Longitudinal Unzipping of Carbon Nanotubes to Form Graphene Nanoribbons [51]. Similarly, N. Liu et presented an Electrochemical Synthesis of Ionic-Liquid-Functionalized Graphene Sheets Directly from Graphite [52]. Chaee, Xin et developed High quality graphene though microwave irradiated expansion. [53]

Primarily there are two types of approaches used in nanofabrication namely:

\section{1) Top down 2) Bottom up}

In bottom up synthesis method nanostructures are synthesized by building or depositing atoms onto each other. A bottom-up approach implies addition of building blocks onto the substrate to form the nanostructures.

In top down approach nanostructures are synthesized by drawing out crystals planes (eradicating crystal planes) present on the substrate. A top-down approach implies removal of building blocks from the substrate to form the nanostructure.

The bottom-up approach is more accurate and practical than the top-down approach as this is capable of producing nanostructures with less imperfections and better chemical composition along with its ability for mass production in large quantities [54] [55] [56].



Figure 2: Schematic presentation of methods used for the formation of graphene-Nano particle hybrids and different structures. [48] Copyright () 2017 Jana et al.; licensee Beilstein-Institute

Types of Nano coatings: 
- Metallic Nano coatings

- Ceramic Nano coatings

- Nanocomposite coatings

\subsection{Metallic Nano Coatings}

Metallic nano coatings are manufacture using pure metals ( $\mathrm{Zn}, \mathrm{Ni}, \mathrm{Co}, \mathrm{Fe}, \mathrm{Tn}, \mathrm{Cu}$ etc) or alloys (Zn-Ni, Co-Ni, Ni-Cu, Co-P, Ni-W etc.). These are generally nano crystalline in nature with grain size ranging from $15 \mathrm{~nm}$ to $250 \mathrm{~nm}$. These are widely used in many critical applications e.g. aerospace, undersea gas pipelines, nuclear and power industry etc. Metallic nano coatings are fabricated using various techniques such as electrochemical deposition, chemical vapor disposition, thermal deposition, spin coatings etc.

\subsection{Ceramic Nano Coatings}

Ceramic nano coatings are made by combining metallic and nonmetallic elements e.g. Titanium Oxides (TiO2), Zirconium oxide, Tantalum Oxide (Ta2O5), Alumina thin films (A12O3). Ceramic oxide coatings are better over metallic or organic oxides in terms of their higher hardness and strength [57]. These are used in industrial applications on account of excellent resistant to oxidation, corrosion, and wear than metals in high-temperature applications [58]. Various techniques developed for fabrication of ceramic nano coatings are sol-gel method [59], atomic layer deposition [60], hydrothermal deposition [61], thermal spraying [62] and ion beam-induced chemical vapour deposition (IBICVD) [63]

\subsection{Nano Composite Coatings}

A nanocomposite is a material composed of at least two different materials those are not miscible, first one is matrix and other is filler. The matrix is the primary part of the composite can be metallic, ceramic, or polymer, with any one dimension larger than nanoscale whereas fillers are actual nanomaterials in the order of nanoscale (e.g. nano particles, nanotubes, nanowires, nano rods ; or nano platelets, nano sheets or nanofilms. The nanocomposite coatings are categorised according to dimension of the fillers [64]. Nanocomposite coatings claims to results in increased mechanical strength along with corrosion resistance. Polymer and metallic matrices nanocomposite coatings are receiving a great attention in industry as protective coatings on account of extraordinary hydrophobic properties. In polymer bases nano coatings, polymers are as host matrices \& nanomaterials are inducted as filler or pigment resulting in hybrid organic-inorganic material [57]. Popularly used nano fillers are CNT [69], Graphene oxide [67,69], $\mathrm{ZrO}$ [69], SiO2 [70]etc with polymer matrix of epoxy, vinyl, epoxy resins and fluoropolymer. Incorporating graphene nanoparticles in polymer matrix has shown a great enhancement in corrosion resistance [69]

\section{GRAPHENE BASED NANO COMPOSITE COATINGS AS PROTECTIVE BARRIER AGAINST ENVIRONMENTAL DAMAGE}

As already discussed excellent properties of graphene make it an ideal material to act as a barrier against various types of environmental damage e,g. corrosion, wear, pitting blistering etc. Commercially, it is difficult to manufacture defect free graphene coatings without pores and micro channels, therefore to ensure technical feasibility and commercial viability graphene based Nano composite are developed. We shall discuss polymeric graphene based nano composite coatings and graphene nano particle composite and their behavior against corrosion, hydrogen embrittlement and other environmental damage mechanisms. 
Many researchers have established that induction of graphene can enhance several properties of polymers such as electrical properties, mechanical properties, chemical reactivity and many more. In 2012 Chang et.al developed an anti-corrosion polyaniline (PANI) based graphene layers for application on steel [71] and demonstrated that graphene alloyed PANI layers exhibits the excellent resistance to electrochemical corrosion \& offer very high efficiency in obstructing oxygen and water. At the same time Pan, Jhao and Zhang worked Polyphenylene Sulfide/Polytetrafluoroethylene Wax Composite Coatings and reinforced it by Graphene to enhance the wear performance [72], they found that the wear characteristics of graphene reinforced composite coating increased by more than four times as compared to that of unalloyed PA coating without any major change in value of friction coefficients. In 2012 Wang and his team used sol-gel method for fabrication of graphene-reinforced waterborne polyurethane coatings [73] and claimed an enormous increase in tensile strength \& Young's modulus by approximately $70 \%$ with an increase in graphene content from 0 to $5 \%$. (by weight) .

In 2014 Tae-Heum Nam and co-workers studied behaviour of graphene coating against hydrogen embrittlement [74]. They concluded that the resistance of copper to HE is increased by providing graphene protective coating, but this behaviour disappeared after a total strain of $25 \%$. This shos that the higher strains result in defects in graphene layers and reduced resistance towards hydrogen permeability.

Jayanta M. and coworkers [75] developed a corrosion resistant composite coating of polypyrrole and graphene oxide for AISI type 304 stainless steel substrates. They used galvanostatic deposition technique for electrodeposition of graphene oxide-polypyrrole composite onto a 304 stainless steel substrate and concluded that this material can be used as an effective corrosion inhibitor.

In 2015 Monetta along with his team conducted study [76] in which hybrid coating was applied to Al 2024 -T3 samples. These hybrid coatings were prepared mixing graphene nano flakes with water-based epoxy resin in an ultrasonic. They demonstrated a considerable improvement in anti-corrosion performances by Electrochemical Impedance Spectroscopy (EIS) analysis.

These studies suggested that the corrosion performance of non-anticorrosive coating system can be an enhanced greatly by adding graphene.

\section{GRAPHENE AS A PROTECTIVE BARRIER FOR HYDROGEN EMBRITTLEMENT}

As discussed in section-1, hydrogen embrittlement is a pronounced concern while using high strength steel in critical applications, demanding an agent to provide a barrier for protection. As explained by various researchers the environmental factor could prove to be a major element responsible for hydrogen ingress into microstructure and any intermediate layer retarding hydrogen permeation into metal would provide an immediate and economical solution without changing any aspect of manufacturing and external environment. Although, researchers have proposed numerous coatings to prevent HE of high strength steel none of them can be termed as ideal \& most applicable solution on account of various limitations e.g. method of production, ease of application, service life in aggressive environment, effect on properties of base material and most important their effectiveness in reducing hydrogen embrittlement.

Graphene offers an excellent impermeability due to its unique geometric \& molecular arrangement. As investigated by Berry in 2013 [79] graphene has geometric pore size of 0.064 $\mathrm{nm}$, which is substantially smaller than the Van Der Waals diameter of small molecules like helium and hydrogen $(0.28 \mathrm{~nm}$ and $0.314 \mathrm{~nm}$, respectively) hence it act as a barrier to hydrogen for permeation from corrosive solution to substrate. 

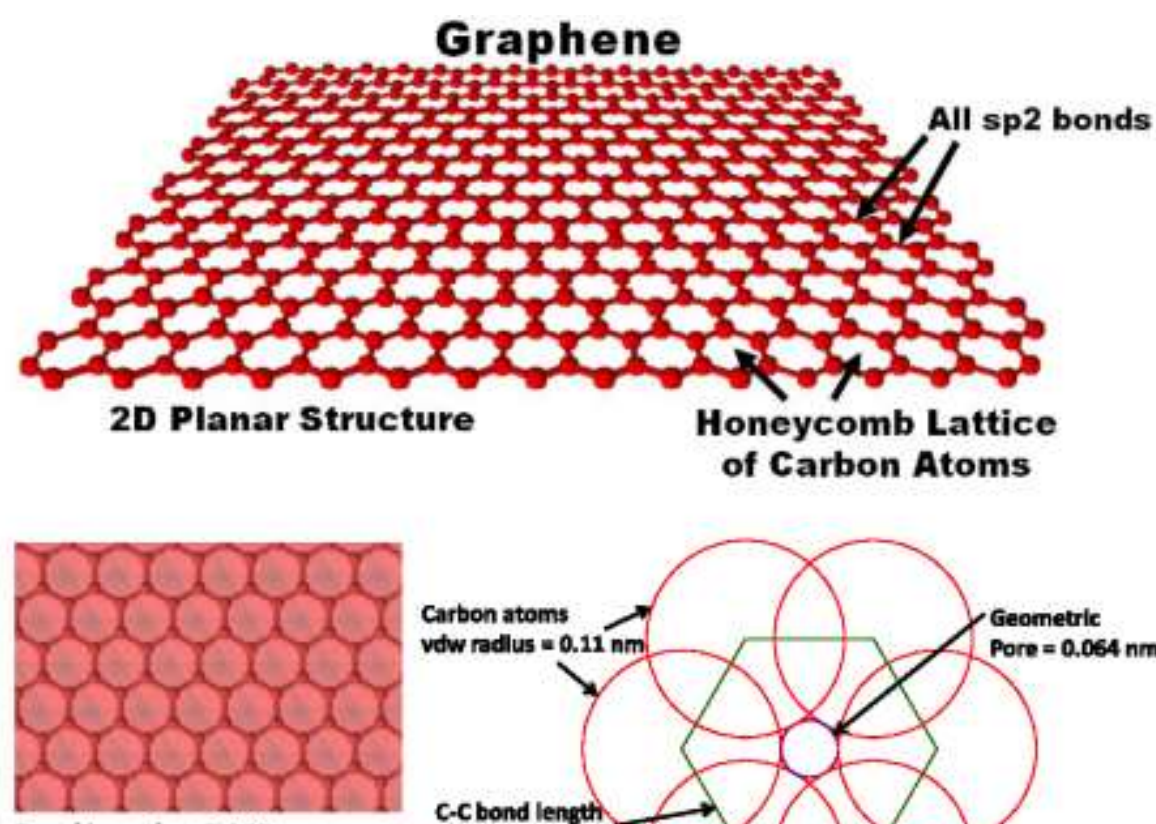

Bond Length $=0.142 \mathrm{~nm}$

C radius (vdw) $=0.11 \mathrm{~nm}$

Rough Electron Density Distribution

e-transparency+ impermeability



Figure 3 Graphene lattice structure: $\mathrm{sp} 2$ hybridized carbon atoms arranged in a 2D honeycomb lattice. it is practically impermeable to all molecules at room temperature. Geometric pore $(0.064 \mathrm{~nm})$ is also small enough not to allow molecules to pass through [79]

In 2017 Zhou and co-workers explained the interaction of hydrogen and graphene [80]. It was revealed that graphene can work as a hydrogen storage material because hydrogen is absorbed by graphene as $\mathrm{C}-\mathrm{H}$ sp3 bonds. Moreover, the energy barrier of forming $\mathrm{C}-\mathrm{H}$ bonds $(0.18 \mathrm{eV})$ in graphene needed to overcome was much lower than that of hydrogen passing through graphene $(2.89 \mathrm{eV})$. As a consequence, $\mathrm{C}-\mathrm{H} \mathrm{sp} 3$ bonds formed from the interaction between hydrogen passing through graphene and graphene incorporated in coatings, which interrupted hydrogen permeation into QP steel substrate.

Yong-Sang Kim \& Jung-Gu Kim in 2017 published their work in which reduced graphene oxide was deposited on stainless steel by an electroplating method and investigated for application as a protective barrier against hydrogen embrittlement [81]. In their experiment researchers used electroplating technique for deposition of reduced graphene oxide was on stainless steel. Subsequently they applied scanning electron microscopy and infrared spectroscopy for evaluation. Specimen were subjected to Slow strain rate tests to determine the hydrogen embrittlement resistance behaviour. They found reduced stress and strain under hydrogen conditions under hydrogen reduction conditions attributed to the formation of reduced graphene oxide; resulted by the formation of hydro-generated graphene and the increased hydrogen diffusion length. 


\section{APPLICATION OF GRAPHENE BASED COATINGS FOR MITIGATION OF HYDROGEN EMBRITTLEMENT}



Figure 4: Application of Graphene Nano coatings for mitigation of Hydrogen Embrittlement

A wide variety of coatings based on graphene and its other derivatives e.g. graphene oxide (GO) displays unique barrier properties against various types of environmental damage namely corrosion, wear and acidic medium. Research conducted in last 10 years implies that the high quality graphene and its composite membranes could be impermeable and exhibit excellent barrier properties to many reactive and gases (e.g. hydrogen, helium) and liquids, salts and acids [56-73] along with high chemical and thermal stability. These features position graphene ahead over other barrier materials available for industrial application. The research done so far establishes that the graphene has the potential to be used as a high-performance barrier coating however application of graphene specific to environment responsible for hydrogen embrittlement required detailed analysis and feasibility study for large-scale industrial applications. Authors attempted to conduct research focusing on development of graphene based nano coatings/ films and to test them on specimens of low alloy high strength steel through a series of experiment under specific conditions accelerating damages on account of hydrogen embrittlement $\&$ evaluating the behaviour.

\section{EXPERIMENTAL INVESTIGATION TO EVALUATE THE BEHAVIOUR OF COATINGS TO MINIMIZE HYDROGEN EMBRITTLEMENT}

Literature indicates numerous events of failure of industrial components on account of hydrogen embrittlement [82]. High strength steels are highly susceptible for hydrogen embrittlement during manufacturing process and during service life [83, 84] for Several coatings are being used in industrial applications to protect the components from environmental damage. Authors have listed following coatings on the basis of their experience and further discussion with industry experts - 
Table 2 Types of Industrial Coatings

\begin{tabular}{|c|l|c|l|}
\hline Sl.No. & \multicolumn{1}{|c|}{ Coating Type } & Sl.No. & \multicolumn{1}{c|}{ Coating Type } \\
\hline 1 & Zinc Flakes coatings & 2 & Zinc Electroplating \\
\hline 3 & Nickle coatings & 4 & Zinc-Ni alloys \\
\hline 5 & Ni-Cobalt alloys & 6 & Zinc-Cobalt electroplating \\
\hline 7 & Cadmium plating & 8 & TiN coatings \\
\hline 9 & Parkerizing / Phosphating & 10 & Black oxide \\
\hline 11 & Electropolishing & 12 & Silicon carbide epoxy coatings \\
\hline 13 & Polymer acrylic coatings & 14 & Teflon (PTFE) \\
\hline 15 & Tin Zinc Alloys & 16 & Zinc \& Al flakes \\
\hline 17 & Graphene Reinforced Composites & 18 & Graphene coatings \\
\hline
\end{tabular}

Following coatings are selected for experimental research to investigate the behavior for minimizing the hydrogen embrittlement

\begin{tabular}{|l|l|}
\hline \multicolumn{1}{|c|}{ Zinc Electroplating } & \multicolumn{1}{c|}{ Ni-Cr alloy } \\
\hline Nickle coatings & Black oxide \\
\hline Polymer acrylic Coatings & Ceramic Coatings \\
\hline Graphene coatings & \\
\hline
\end{tabular}

\section{MATERIAL \& METHODOLOGY}

In order to investigate the behavior of selected coatings in the environment promoting hydrogen embrittlement, specimen of EN24 are manufactured. Commercially available ready to use hardened and tempered high strength steel EN24 / AISI 4340 is used to analyze the effect of HE under different condition of hydrogen charging. EN24T steel having good machinability and claims a good high tensile steel strength with resilience, hardness and wear resistance. It has a tensile strength of 800/1200 MPa. EN24 being used in the automobiles and tool industries for fasteners, gears, shafts, pinions, spindles etc.

Chemical and mechanical properties of EN24 are indicated in Table 3 and 4. The material used with two heat treatment conditions namely $\mathrm{T} \& \mathrm{X}$ differentiated by heat treatment cycle and UTS.

Table 3- EN24Chemical properties

\begin{tabular}{|l|l|l|l|}
\hline Carbon & $0.35-0.45 \%$ & Silicon & $0.10-0.35 \%$ \\
\hline Nickel & $1.30-1.80 \%$ & Manganese & $0.45-0.70 \%$ \\
\hline Chromium & $0.90-1.40 \%$ & Phosphorus & $0.05 \% \max$ \\
\hline Molybdenum & $0.20-0.35 \%$ & Sulphur & $0.05 \% \max$ \\
\hline
\end{tabular}

Table 4 - EN24Mechanical Properties

\begin{tabular}{|c|c|c|c|c|c|}
\hline Grade & U.T.S. (MPa) & $\begin{array}{c}\text { Yield } \\
\text { (MPa) }\end{array}$ & Elongation(\%) & $\begin{array}{c}\text { Impact(KCV) } \\
\text { J }\end{array}$ & HardnessBrinell \\
\hline $\mathrm{T}$ & $850-1000$ & 650 & 13 & 35 & $248-302$ \\
\hline $\mathrm{U}$ & $925-1075$ & 855 & 12 & 42 & $269-331$ \\
\hline $\mathrm{V}$ & $1000-1150$ & 750 & 12 & 42 & $293-352$ \\
\hline $\mathrm{W}$ & $1075-1225$ & 940 & 11 & 35 & $311-375$ \\
\hline $\mathrm{X}$ & $1150-1300$ & 1020 & 10 & 28 & $341-401$ \\
\hline $\mathrm{Y}$ & $1225-1375$ & 1095 & 10 & 21 & $363-429$ \\
\hline $\mathrm{Z}$ & 1550 & 1235 & 5 & 9 & 444 \\
\hline
\end{tabular}


For assessment of HE performance of the material, tensile tests of charged specimen are carried out at controlled strain rate in air. Hydrogen charging of the specimen done by cathodic reaction. $0.5 \mathrm{M} \mathrm{H}_{2} \mathrm{So}_{4}$ Solution was prepared. During preparation of solution, a concentrated $\mathrm{H} 2 \mathrm{So} 4$ Solution is mixed with water is right proportion. In a 1 litre of volumetric flask, $53.3 \mathrm{ml}$ of concentrated H2So4 Solution is required. By using this a dilute H2So4 Solution is prepared and cathodic reaction performed for hydrogen diffusion in high strength steel. For cathodic reaction, test specimen is made cathode and platinum wire is used as anode. Hydrogen changing done with current density of $20 / 40 / 60 \mathrm{~mA} / \mathrm{cm}^{2}$ for a duration of $4 \& 8 \mathrm{hrs}$ for each type of coatings. The tensile test conducted30mins after hydrogen-charging process was finished. Charged specimen are tested using slow strain rate test (SSRT) to determine the effect on tensile $\&$ yield strength and \& elongation.



Figure 5 Hydrogen Charging of test specimen

Table 5 - Testing conditions for Mechanical Test

\begin{tabular}{|c|c|c|}
\hline Condition & H-charging Current Densitv & H-charging Time \\
\hline 1 & - & No Charging \\
\hline 2 & $20 \mathrm{~mA} / \mathrm{cm}^{2}$ & $4 \mathrm{hrs}$ \\
\hline 3 & $40 \mathrm{~mA} / \mathrm{cm}^{2}$ & $4 \mathrm{hrs}$ \\
\hline 4 & $60 \mathrm{~mA} / \mathrm{cm}^{2}$ & $4 \mathrm{hrs}$ \\
\hline
\end{tabular}

\section{RESULTS}

Following graphs are plotted using the results of SSRT test indicating yield strength, tensile strength and \% elongation of test specimen coated with various types of coatings.

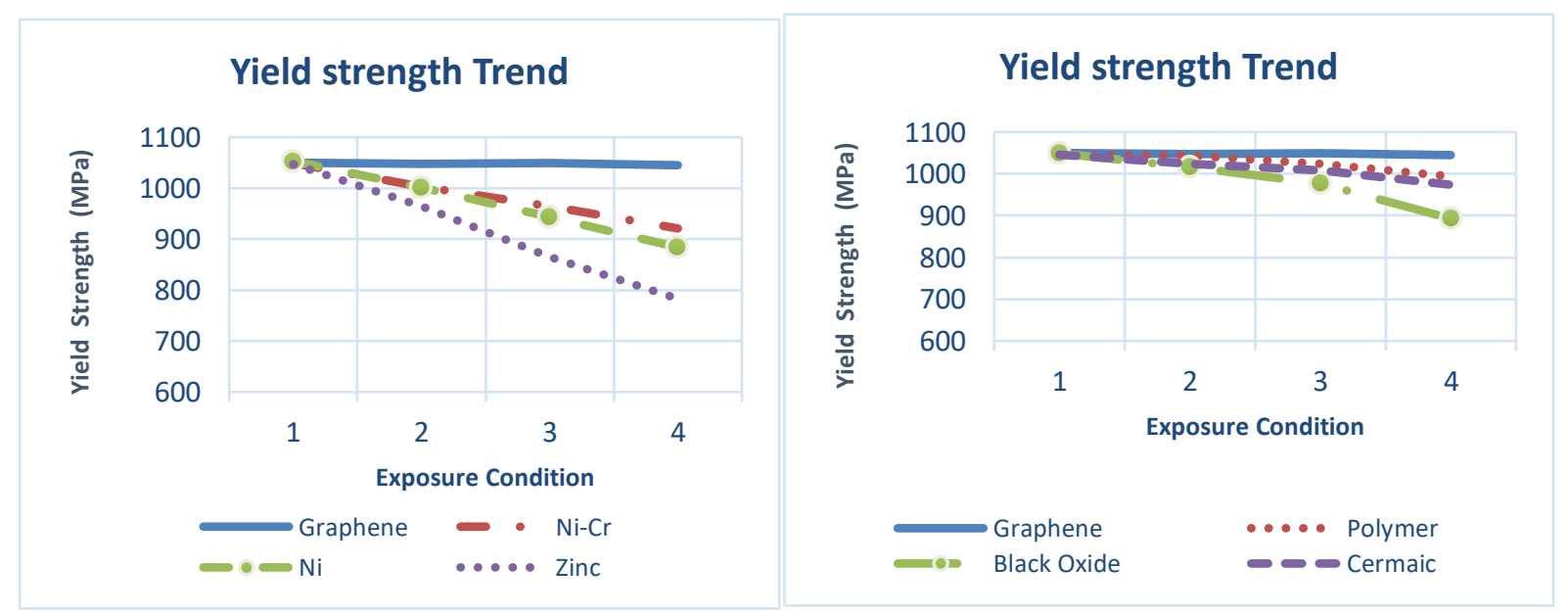

Figure 6 Yield strength trends for various condition of charging 


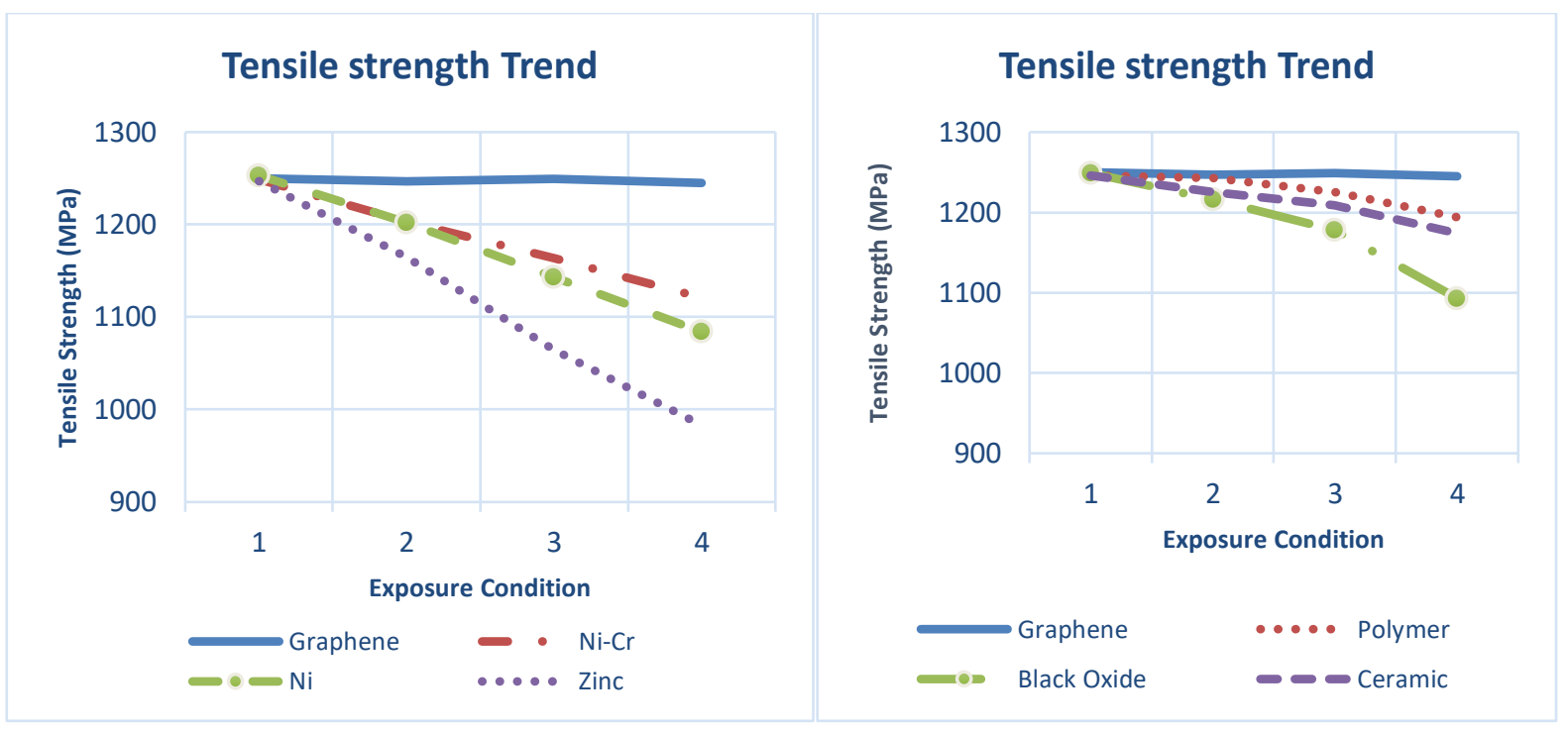

Figure 7 Tensile strength trends for various condition of charging

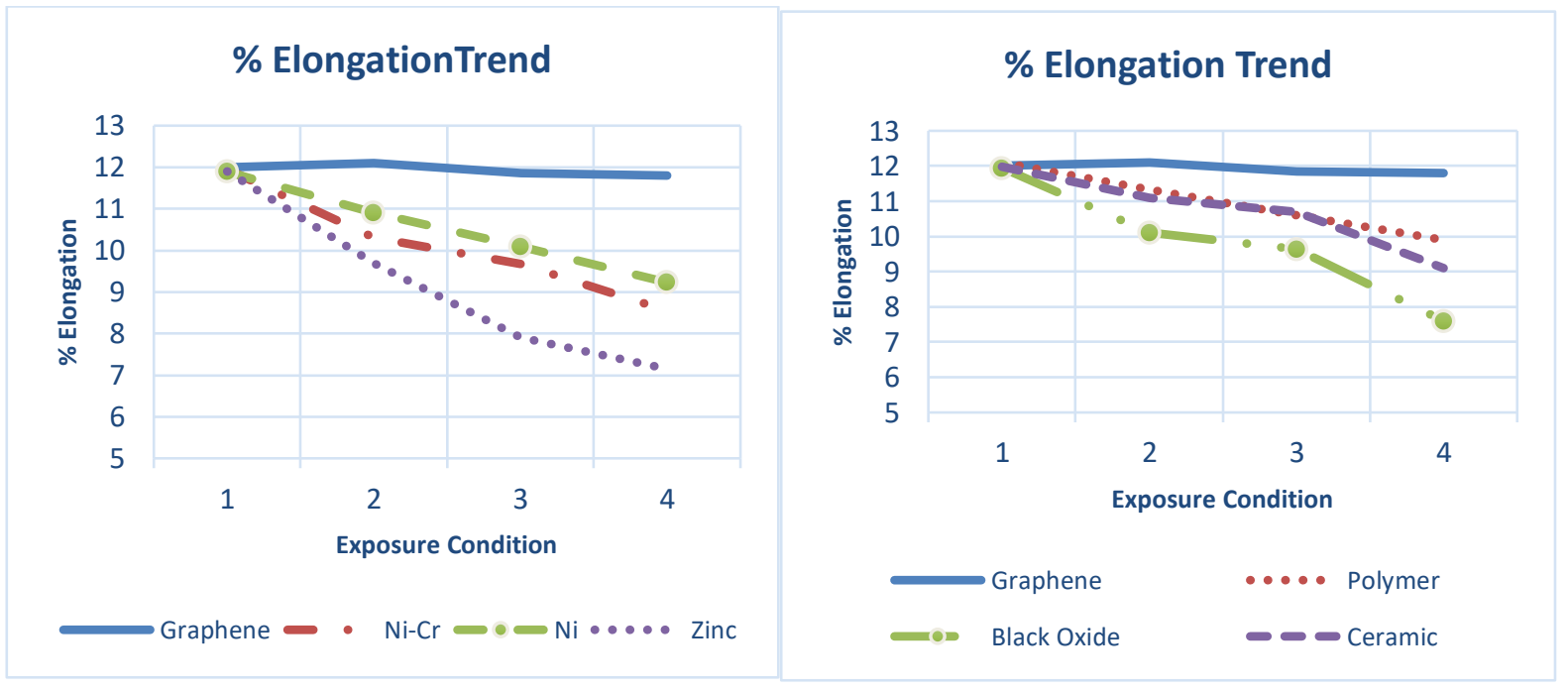

Figure $8 \%$ Elongation trends for various condition of charging

\section{DISCUSSION ON RESULTS}

Tensile \& yield strength graphs indicate that the specimen coated with graphene are least affected by hydrogen charging. It can be seen that the tensile and yield strength of graphene coated specimen remains unchanged under various condition of hydrogen charging, whereas these are reduced considerable when tested for other types of coatings under identical condition of charging. Similarly, there is a reduction in \% elongation with charging time and voltage for various coatings except graphene. Trends established in mechanical testing of specimens under cathodic charging indicates the superior performance graphene coatings as against of other coatings for similar environmental conditions. The graphene coated specimens are found to perform better for minimizing the hydrogen embrittlement of high strength steel.

The experimental results suggest the graphene based Nano coatings have promising performance and can be successfully applied on high strength steel to combat with hydrogen embrittlement. 


\section{REFERENCES}

[1] Johnson WH. On some remarkable changes produced in iron and steels by the action of hydrogen acids. Proc R Soc Lond 1875, 23,168-79.

[2] ASTM G193-12d. Standard terminology and acronyms relating to corrosion. West Conshohocken: ASTM International; 2012.

[3] ASTM F2078 Standard Terminology Relating to Hydrogen Embrittlement Testing.

[4] Brahimi S. Fundamentals of hydrogen embrittlement in steel fasteners. IBECA Technology Corp. 2014

[5] Herring DH. Hydroqen Embrittlement. Wire Forming Technology International. 2010; 13 (4), 24-7.

[6] Davis JR. Metals handbook. ASM international; 1998

[7] O. RA, H. JP, and S. M, Hydrogen degradation of ferrous alloys, William Andrew Publishing, Noyes, 1985

[8] Troiano AR. The role of hydrogen and other interstitials in the mechanical behavior of metals. Trans ASM 1960, 52, 54-80.

[9] Song J, Curtin WA. Atomic mechanism and prediction of hydrogen embrittlement in iron. Nature materials. $2013 \mathrm{Feb}$; 12(2):145.

[10] Birnbaum HK, Sofronis P. Hydrogen-enhanced localized plasticity-a mechanism for hydrogen-related fracture. Materials Science and Engineering: A. 1994 Mar 31; 176 (12):191-202.

[11] Kim SJ, Jung HG, Kim KY. Effect of post-weld heat treatment on hydrogen-assisted cracking behavior of high-strength process pipe steel in a sour environment. Scripta Materialia.2012 Dec 1; 67 (11):895-8.

[12] Yamauchi Y, Takeda K, Nobuta Y, Hino T. Hydrogen and helium removal retained in stainless steel by neon glow discharge. J Nucl Mater 2009, 390-391, 1048-50.

[13] Elboujdaini M, Sastri VS, Perumareddi JR. Studies on inhibition of hydrogen-induced cracking of linepipe steels. Corrosion. 2006 Jan; 62 (1):29-34.

[14] Wikipedia (link https://en.wikipedia.org/wiki/Nanomaterials)

[15] Singh R. Corrosion control for offshore structures: cathodic protection and high-efficiency Coating. Gulf Professional Publishing; 2014 Aug 12.

[16] Samimi A, Zarinabadi S. An analysis of polyethylene coating corrosion in oil and gas pipelines. Journal of American science, USA. 2011.

[17] Van Velson, N.; Flannery, M. Performance Life Testing of a Nanoscale Coating for Erosion and Corrosion Protection in Copper Microchannel Coolers. In Proceedings of the 15th IEEE Intersociety Conference on Thermal and Thermomechanical Phenomena in Electronic Systems (ITherm), Las Vegas, NV, USA, 31, 2016, 662-669.

[18] Saji VS. The impact of nanotechnology on reducing corrosion cost. InCorrosion Protection and Control Using Nanomaterials 2012 Jan 1 (pp. 3-15). Woodhead Publishing.

[19] Mingming, Y.; Yedong, H.; Ying, Z.; Quixia, Y. Al2O3-Y2O3 Nano- and Micro-composite coatings on Fe-9Cr-Mo. J. Rare Earth 2006, 24, 587-590.

[20] Dariva CG, Galio AF. Corrosion inhibitors-principles, mechanisms and applications. InDevelopments in corrosion protection $2014 \mathrm{Feb} 20$. IntechOpen.

[21] Liu JL, Bashir S. Advanced nanomaterials and their applications in renewable energy. Elsevier; 2015 Aug 6. 
[22] Schaefer HE. Carbon Nanostructures-Tubes, Graphene, Fullerenes, Wave-Particle Duality. In Nanoscience 2010 (pp. 209-266). Springer, Berlin, Heidelberg.

[23] Yousaf S, Alhnan MA, Abdallah A, Abdallah B, Khan I, Ahmed W. Nanocoatings in medicine: Antiquity and modern times. InEmerging Nanotechnologies for Manufacturing 2015 Jan 1 (pp. 418-443). William Andrew Publishing.

[24] Van Lente H, van Til JI. Articulation of sustainability in the emerging field of nanocoatings. Journal of Cleaner Production. 2008 May 1; 16 (8-9):967-76.

[25] Schuh, C.A.; Nieh, T.G.; Iwasaki, H. The effect of solid solution W additions on the mechanical properties of nanocrystalline Ni. Acta Mater. 2003, 51, 431-443.

[26] Sriraman, K.R.; Strauss, H.W.; Brahimi, S.; Chromik, R.R.; Szpunar, J.A.; Osborne, J.H.; Yue, S. Tribological behavior of electrodeposited $\mathrm{Zn}, \mathrm{Zn}-\mathrm{Ni}, \mathrm{Cd}$ and $\mathrm{Cd}-\mathrm{Ti}$ coatings on low carbon steel substrates. Tribiol. Int. 2012, 56, 107-120.

[27] Andreatta, F.; Aldighieri, P.; Paussa, L.; Di Maggio, R.; Rossi, S.; Fedrizzi, L. Electrochemical behaviour of $\mathrm{ZrO} 2$ sol-gel pre-treatments on AA6060 aluminium alloy. Electrochim. Acta 2007, 52, 7545-7555.

[28] Wang, Y.; Zhang, L.; Hu, Y.; Li, C. Comparative Study on Optical Properties and Scratch Resistance of Nanocomposite Coatings Incorporated with Flame Spray Pyrolyzed Silica Modified via in-situ Route and ex-situ Route. J. Mater. Sci. Technol. 2016, 32, 251-258.

[29] Ma, J.; Xu, J.; Jiang, S.; Munroe, P.; Xie, Z. Effectsof pH value and temperature on the corrosion behavior of a Ta2N nanoceramic coating in simulated polymer electrolyte membrane fuel cell environment. Ceram. Int. 2016, 42, 16833-16851.

[30] V. Sherin and M. Kalaivani, Compression Behaviour of SelfCompacting Concrete Columns Using High Strength Steel Wires as External Confinement, International Journal of Civil Engineering and Technology, 9(11), 2018, pp. 1692-1699

[31] Hibbard, G.; Aust, K.T.; Palumbo, G.; Erb, U. Thermal Stability of Electrodeposited Nanocrystalline Cobalt. Scr. Mater. 2001, 44, 513-518.

[32] McGee JD, Smith IT, Bammel BD, Bryden TR, inventors; Henkel AG and Co KGaA, assignee. Release on demand corrosion inhibitor composition. United States patent US 8,241,524. 2012 Aug 14.

[33] Wang D, Sikora E, Shaw B. A Comparison of the Corrosion Response of Zinc-Rich Coatings with and Without Presence of Carbon Nanotubes under Erosion and Corrosion Conditions. Corrosion. 2018 Jul 30; 74 (11):1203-13.

[34] Boostani H, Modirrousta S. Review of nanocoatings for building application. Procedia Engineering. 2016 Jan 1; 145: 1541-8.

[35] Khanna, A.S. Nanotechnology in High Performance Paint Coatings. Asian J. Exp. Sci. 2008, 21, 25-32.

[36] Beyene, F.G. A review on nanocoating of metallic structures to improve hardness and maintaining toughness. I-Manager's J. Mater. Sci. 2016, 4, 32-41.

[37] Mahapatro A. Bio-functional nano-coatings on metallic biomaterials. Materials Science and Engineering: C. 2015 Oct 1; 55: 227-51.

[38] Wunderlich, W. The Atomistic Structure of Metal/Ceramic Interfaces is the Key Issue for Developing Better Properties. Metals 2014, 4, 410-427.

[39] Novoselov KS, Geim AK, Morozov SV, Jiang D, Zhang Y. Dubonos SV, et al. Electric field effect in atomically thin carbon films. Science. 2004; 306, 666-669. 
[40] K. S. Novoselov, A. K. Geim, S. V. Morozov, D. Jiang, M. I. Katsnelson, I. V. Grigorieva, S. V. Dubonos, and A. A. Firsov, Two-dimensional gas of massless Dirac fermions in graphene Nature (London), 2005, 438, 197.

[41] Geim AK, Novoselov KS. The rise of graphene. InNanoscience and Technology: A Collection of Reviews from Nature Journals 2010 (pp. 11-19).

[42] Pop, Eric, Vikas Varshney, and Ajit K. Roy. "Thermal properties of graphene: Fundamentals and applications." MRS bulletin 37, 2012, 12, 1273-1281.

[43] "Nobel Physics Laureates" (PDF). nobelprize.org. [online] https://selectra.co.uk/sites/default/files/pdf/advanced-physicsprize2010.pdf

[44] Rafiee MA, Rafiee J, Wang Z, Song H, Yu ZZ, Koratkar N. Enhanced mechanical properties of nanocomposites at low graphene content. ACS nano. 2009 Dec 3; 3 (12):388490.

[45] Lang, B.: A LEED study of the deposition of carbon on platinum crystal surfaces. Surface Science 1975, 53(1), 317-329

[46] Lu, X.K., Huang, H., Nemchuk, N., Ruoff, R.S.: Patterning of highly oriented pyrolytic graphite by oxygen plasma etching.Appl. Phys. Lett. 1999, 75, 193. doi:10.1063/1.124316

[47] Park, S. and Ruoff, R.S. Chemical Methods for the Production of Graphenes. Nature Nanotechnology, 2009, 4, 217-224.

[48] Allen, M.J., Tung, V.C. and Kaner, R.B. Honeycomb Carbon: A Review of Graphene. Chemical Reviews, 2010, 110, 132-145.

[49] Jana, A.; Scheer, E.; Polarz, S. Beilstein, Synthesis of graphene-transition metal oxide hybrid nanoparticles and their application in various fields J. Nanotechnol. 2017, 8, 688714.

[50] Rollings E, Gweon GH, Zhou SY, Mun BS, McChesney JL, Hussain BS, Fedorov AV, First PN, De Heer WA, Lanzara A. Synthesis and characterization of atomically thin graphite films on a silicon carbide substrate. Journal of Physics and Chemistry of Solids. $2006 \mathrm{Sep}$ 1;67 (9-10):2172-7.

[51] Reina A, Jia X, Ho J, Nezich D, Son H, Bulovic V, Dresselhaus MS, Kong J. Large area, few-layer graphene films on arbitrary substrates by chemical vapor deposition. Nano letters. 2008 Dec 1;9 (1):30-5.

[52] Kosynkin DV, Higginbotham AL, Sinitskii A, Lomeda JR, Dimiev A, Price BK, Tour JM. Longitudinal unzipping of carbon nanotubes to form graphene nanoribbons. Nature. 2009 Apr; 458 (7240):872.

[53] Liu, N., Luo, F., Wu, H., Liu, Y., Zhang, C. and Chen, J. One-Step Ionic- Liquid-Assisted Electrochemical Synthesis of Ionic-Liquid-Functionalized Graphene Sheets Directly from Graphite. Advanced Functional Materials, (2018), 18, 1518-1525.

[54] Xin, G., Hwang, W., Kim, N., Cho, S.M. and Chae, H. A Graphene Sheet Exfoliated with Microwave Irradiation and Interlinked by Carbon Nanotubes for High-Performance Transparent Flexible Electrodes. Nanotechnology, 2010, 21.

[55] Deon Neveling, Difference between top down and bottom up methods for creating nanostructures Stellenbosch University, post on Researchgate [online]

[56] Warner J.H., Scha Ffel F, Bachmatiuk A, R Ummeli M.H., Graphene: Fundamentals and emergent applications, Elsevier, Oxford, 2012.

[57] Shams SS, Zhang R, Zhu J. Graphene synthesis: a Review. Materials Science-Poland. 2015 Sep 1;33 (3):566-78. 
[58] Watchman, J.D.; Haber, R.A. Ceramic Films and Coatings-An overview. In Ceramic Films and Coatings; Noyes Publications: New York, NY, USA, 1993.

[59] Callister Jr WD, Rethwisch DG. Fundamentals of materials science and engineering: an integrated approach. John Wiley \& Sons; 2012.

[60] Atik M, de Lima Neto P, Avaca LA, Aegerter MA. Sol-gel thin films for corrosion protection. Ceramics International. 1995 Jan 1;21 (6):403-6.

[61] Shan CX, Hou X, Choy KL. Corrosion resistance of TiO2 films grown on stainless steel by atomic layer deposition. Surface and Coatings Technology. 2008 Feb 25;202(11):2399-402.

[62] Garg, N.; Bera, S.; Mangamma, G.; Das, C.R.; Kamaruddin, S.; Velmurugan, S. Electrochemical and adhesion properties of hydrothermally deposited nano-ZrO2 coatings on oxide layers of stainless steel. Surf. Coat. Technol. 2015, 281, 98-108

[63] Richard C, Kowandy C, Landoulsi J, Geetha M, Ramasawmy H. Corrosion and wear behavior of thermally sprayed nano ceramic coatings on commercially pure Titanium and $\mathrm{Ti}-13 \mathrm{Nb}-13 \mathrm{Zr}$ substrates. International Journal of Refractory Metals and Hard Materials. 2010 Jan 1;28(1):115-23.

[64] Holgado, J.P.; Yubero, F.; Espinos, J.P. Corrosion resistant $\mathrm{ZrO} 2$ thin films prepared at room temperature by ion beam induced chemical vapour deposition. Surf. Coat. Technol. 2002, 152, 449-453.

[65] Nguyen-Tri, P.; Nguyen, T.A.; Carriere, P.; Ngo Xuan, C. Nanocomposite Coatings: Preparation, Characterization, Properties, and Applications. Int. J. Corros. 2018, 474-501.

[66] Mittal V. Polymer nanocomposites: synthesis, microstructure, and properties. Optimization of polymer nanocomposite properties. 2010 Jan 13:1-9.

[67] Oliveira M, Machado AV. Preparation of polymer-based nanocomposites by different routes. 2013, 1-22.

[68] Fayyad EM, Sadasivuni KK, Ponnamma D, Al-Maadeed MA. Oleic acid-grafted chitosan/graphene oxide composite coating for corrosion protection of carbon steel. Carbohydrate polymers. 2016 Oct 20;151:871-8.

[69] Aglan A, Allie A, Ludwick A, Koons L. Formulation and evaluation of nano-structured polymeric coatings for corrosion protection. Surface and Coatings Technology. 2007 Nov 25;202(2):370-8.

[70] Di, H.; Yu, Z.; Ma, Y.; Zhang, C.; Li, F.; Lv, L.; Pan, Y.; Shi, H.; He, Y. Corrosion-resistant hybrid coatings based on graphene oxide-zirconia dioxide/epoxy system. J. Taiwan Inst. Chem. Eng. 2016, 67, 511-520.

[71] Chen L, Song RG, Li XW, Guo YQ, Wang C, Jiang Y. The improvement of corrosion resistance of fluoropolymer coatings by $\mathrm{SiO} /$ poly (styrene-co-butyl acrylate) nanocomposite particles. Applied Surface Science. 2015 Oct 30; 353:254-62.

[72] Chang CH, Huang TC, Peng CW, Yeh TC, Lu HI, Hung WI, Weng CJ, Yang TI, Yeh JM. Novel anticorrosion coatings prepared from polyaniline/graphene composites. Carbon. 2012 Nov 1; 50(14):5044-51.

[73] Pan B, Zhao J, Zhang Y, Zhang Y. Wear Performance and Mechanisms of Polyphenylene Sulfide/Polytetrafluoroethylene Wax Composite Coatings Reinforced by Graphene. J Macromol Sci Part B. 2012, 51, 1218-1227.

[74] Wang X, Xing W, Song L, Yang H, Hu Y, Yeoh GH. Fabrication and characterization of graphene-reinforced waterborne polyurethane nanocomposite coatings by the sol-gel method. Surface and Coatings Technology. 2012 Jul 15; 206(23):4778-84.. 
[75] Nam TH, Lee JH, Choi SR, Yoo JB, Kim JG. Graphene coating as a protective barrier against hydrogen embrittlement. International journal of hydrogen energy. 2014 Jul 24; 39 (22):11810-7.

[76] Mondal J, Marandi M, Kozlova J, Merisalu M, Niilisk A, Sammelselg V. Protection and functionalizing of stainless steel surface by Graphene Oxide-Polypyrrole composite coating. J. Chem. 2014; 8:786-93.

[77] K.V. Ramana, K.S.K. Mallik, K. Narasimhakalyan, A. Mani Ratnam, G. Prasanth Kumar and P. Ravi Teja, Nano coatings as Bearing Liners-An experimental investigation, International Journal of Mechanical Engineering and Technology, 9(5), 2018, pp. 58-63.

[78] Monetta, T.; Acquesta, A.; Bellucci, F.: Graphene/epoxy coating as multifunctional material for aircraft structures. Aerospace 2, 2015, 423-434

[79] Wang X, Qi X, Lin Z, Battocchi D. Graphene Reinforced Composites as Protective Coatings for Oil and Gas Pipelines. Nanomaterials. 2018 Dec;8(12):1005.

[80] Su Y, Kravets VG, Wong SL, Waters J, Geim AK, Nair RR. Impermeable barrier films and protective coatings based on reduced graphene oxide. Nature communications. $2014 \mathrm{Sep}$ 11;5:4843.

[81] S Vijaya Kumar Reddy, Premkartikkumar SR, Radha Krishna Gopidesi and Nitin Uttamrao Kautkar, A Review on Nano Coatings for Ic Engine Applications, International Journal of Mechanical Engineering and Technology 8(9), 2017, pp. 70-76.

[82] Berry V. Impermeability of graphene and its applications. Carbon. 2013 Oct 1;62:1-0.

[83] Zhou P, Li W, Zhu X, Li Y, Jin X, Chen J. Graphene containing composite coatings as a protective coatings against hydrogen embrittlement in quenching \& partitioning high strength steel. Journal of The Electrochemical Society. 2016 Jan 1;163(5):D160-6.

[84] Y.S. Kim, J.G. Kim, Electroplating of reduced-graphene oxide on austenitic stainless steel to prevent hydrogen embrittlement Int J Hydrogen Energy, 2017, 42 (44), 27428-27437

[85] Khare A, Vishwakarma M, Parashar V. A Review on Failures of Industrial Components due to Hydrogen Embrittlement \& Techniques for Damage Prevention. International Journal of Applied Engineering Research. 2017;12(8):1784-92.

[86] Khare A, Dwivedi SK, Vishwakarma M, Ahmed S. Experimental Investigation of Hydrogen Embrittlement during Coating Process and Effect on Mechanical Properties of High Strength Steel used for Fasteners. Materials Today: Proceedings. 2018 Jan 1;5(9):18707-15.

[87] Dwivedi SK, Vishwakarma M. Hydrogen embrittlement in different materials: A review. International Journal of Hydrogen Energy. 2018 Nov 15;43(46):21603-16. 